\title{
Non-criteria manifestations of antiphospholipid syndrome: An overview
}

\author{
Gilberto Pires-da-Rosa, Gerard Espinosa, and Ricard Cervera* \\ Department of Autoimmune Diseases, Hospital Clínic, Institut d'Investigacions Biomèdiques August Pi i Sunyer (IDIBAPS), Universidad de \\ Barcelona, Barcelona, Spain
}

\begin{abstract}
While the classification criteria for definite antiphospholipid syndrome (APS) include specific thrombotic and obstetric manifestation, there are numerous clinical features also present in patients with antiphospholipid antibodies (aPL), which are not included in the classification criteria. The term "non-criteria" is currently used to refer to these manifestations. This review intends to provide a summarized, but far-reaching description, of the non-criteria manifestations present in the literature, with special focus on their association with APS and potential impact on the disease course. We analyze the following involvements: cardiac (cardiac microvascular disease and valvular heart disease), dermatological (livedo reticularis/racemosa, livedoid vasculopathy and skin ulcers), ear, nose, and throat (sensorineural hearing loss), endocrinological (adrenal insufficiency due to hemorrhagic infarction), hematological (hemolytic anemia and thrombocytopenia), musculoskeletal (ischemic bone necrosis), neurological (acute ischemic encephalopathy, chorea, cognitive dysfunction, epilepsy/seizures, migraine, and transverse myelitis), pulmonary (diffuse alveolar hemorrhage and pulmonary hypertension), ophthalmologic (amaurosis fugax), renal (APS nephropathy), vascular (superficial vein thrombosis), and obstetric (infertility, in vitro fertilization failure, and placenta-mediated complications) manifestations. Although gaining relevance in the current practice, the exact level of association of the different non-criteria manifestations with APS/aPL is still unclear or scarcely characterized in most cases.
\end{abstract}

Key words: Antiphospholipid syndrome. Antiphospholipid antibodies. Non-criteria manifestations.

\section{Introduction}

The 2006 classification criteria for definite antiphospholipid syndrome (APS) include specific manifestations - either thrombotic (arterial, venous, or small-vessel) or obstetric ${ }^{1}$. However, there are several additional manifestations that are also present in patients with antiphospholipid antibodies (aPL), but not included in the classification criteria. The term "non-criteria" manifestations has been gradually and informally adopted throughout the literature to refer to these clinical features, and a rising number of publications discuss their relevance ${ }^{2,3}$. The 2014 report of the $14^{\text {th }}$ International Congress on aPL Technical Task Force on APS Clinical Features suggested the inclusion of some manifestations as part of APS criteria revision?. In the initiative for Development of New International APS Classification Criteria, currently underway, many of these non-criteria manifestation are analyzed as candidate criteria ${ }^{4}$. A recent article approaches the treatment of some of these manifestations, namely

Visual abstract available at https://www.spanishjmed.com/frame_esp.php?id=38

\section{Correspondence:}

${ }^{*}$ Ricard Cervera

E-mail: rcervera@clinic.cat
Date of reception: 03-02-2021

Date of acceptance: 12-02-2021

DOI: 10.24875/SJMED.21000003
Available online: 21-06-2021

Span J Med. 2021;1(2):99-107

www.spanishjmed.com

2696-5631 / @ 2021 Sociedad Española de Medicina Interna. Published by Permanyer. This is an open access article under the CC BY-NC-ND license (http://creativecommons.org/licenses/by-nc-nd/4.0/). 
cardiac, pulmonary, hematologic, cutaneous, and neurological involvements ${ }^{5}$.

In this review, we intend to cover, in a summarized but far-reaching manner, the existing "non-criteria" manifestations described in the literature (Table 1), focusing on the strength of their association with aPL and their potential impact on the disease course, and allowing for a general view of this subject.

\section{Cardiac manifestations}

\section{Cardiac microvascular disease}

There are case reports of APS patients with diffuse cardiomyopathy or evidence of myocardial ischemia with normal coronaries, indicating microvascular disease as a plausible mechanism ${ }^{6,7}$. Histology of these patients may reveal occlusive microthrombosis of small myocardial arterioles and areas of micro-infarction surrounding the affected arterioles, with consequential myocardial necrosis ${ }^{6}$. This situation occurs both in classic and catastrophic APS patients ${ }^{8}$. The absence of vasculitis changes in these patients supports the hypothesis that aPL exert a direct thrombotic effect ${ }^{6,9}$. In the Phase III of the Development of New International Classification Criteria for APS, microvascular disease (including cardiac microvascular disease) occurred with higher frequency in cases categorized as "highly likely" to have an APS diagnosis ${ }^{4}$.

\section{Valvular heart disease}

Valvular disease in APS occurs in the form of valve lesions (thickening or vegetations) and/or valve dysfunction in the absence of rheumatic fever or infective endocarditis ${ }^{6}$. Valve lesions are defined as (i) valve thickness $>3 \mathrm{~mm}$; (ii) localized thickening involving the proximal or middle portion of the leaflets; or (iii) irregular nodules on the atrial face of the mitral valve and/or the vascular face of the aortic valve ${ }^{2}$. The reported frequency in primary APS ranges from $10 \%$ to more than $60 \%{ }^{10}$. Histopathological findings may include fibrosis, calcification, vascular proliferation, verrucous thrombosis on endocardial valvular surfaces, and thrombosis of intravalvular capillaries ${ }^{6}$. Possible pathogenic mechanisms for these lesions in aPL patients include both thrombotic and inflammatory mechanisms, such as deposition of aPL and complement components or the deposition of fibrin platelet thrombi on the affected valve ${ }^{10}$. Although the role of aPL in heart lesions has not been categorically proven, most studies
Table 1. Non-criteria manifestations of the antiphospholipid syndrome

\begin{tabular}{|c|c|}
\hline Affected organ/system & Non-criteria manifestation \\
\hline Cardiac & $\begin{array}{l}\text { Cardiac microvascular disease } \\
\text { Valvular heart disease }\end{array}$ \\
\hline Dermatological & $\begin{array}{l}\text { Livedo reticularis/racemosa } \\
\text { Livedoid vasculopathy } \\
\text { Skin ulcers } \\
\text { Splinter hemorrhages }\end{array}$ \\
\hline Ear, nose, and throat & Sensorineural hearing loss \\
\hline Endocrinological & $\begin{array}{l}\text { Adrenal insufficiency due to } \\
\text { hemorrhagic infarction }\end{array}$ \\
\hline Hematological & $\begin{array}{l}\text { Evans syndrome } \\
\text { Hemolytic anemia } \\
\text { Positive Coombs' test } \\
\text { Thrombocytopenia }\end{array}$ \\
\hline Musculoskeletal & Ischemic bone necrosis \\
\hline Neurological & $\begin{array}{l}\text { Acute ischemic encephalopathy } \\
\text { Brain MRI white matter lesions } \\
\text { Chorea } \\
\text { Cognitive dysfunction } \\
\text { Epilepsy/seizures } \\
\text { Migraine } \\
\text { Pseudo-multiple sclerosis } \\
\text { Transverse myelitis }\end{array}$ \\
\hline Pulmonary & $\begin{array}{l}\text { Diffuse alveolar hemorrhage } \\
\text { Pulmonary hypertension }\end{array}$ \\
\hline Ophthalmological & Amaurosis fugax \\
\hline Renal & APS nephropathy \\
\hline Vascular & $\begin{array}{l}\text { Superficial vein thrombosis } \\
\text { Raynaud's phenomenon }\end{array}$ \\
\hline Obstetric & $\begin{array}{l}\text { Infertility } \\
\text { Late intrauterine growth } \\
\text { restriction (after } 34 \text { weeks) } \\
\text { Late pre-eclampsia (after } 34 \text { weeks) } \\
\text { Abruptio placentae } \\
\text { Placental hematoma } \\
\text { Preterm birth (> } 34-<37 \text { weeks) } \\
\text { Puerperal pre-eclampsia } \\
\text { Two or more unexplained IVF failures } \\
\text { Two unexplained spontaneous } \\
\text { abortion }<10 \text { weeks }\end{array}$ \\
\hline
\end{tabular}

APS: antiphospholipid syndrome; IVF: in vitro fertilization; MRI: magnetic resonance imaging.

evaluated in two systematic reviews display an association between the presence of aPL and valvular lesions ${ }^{11,12}$. The risk of valvular heart disease was highest for lupus anticoagulant (LA) and anticardiolipin antibodies (aCL) of the IgG isotype ${ }^{12}$. The report of the $14^{\text {th }}$ International Congress on aPL Technical Task Force on APS Clinical Features classified the evidence regarding valvular heart disease as of "moderate" 
quality, issuing a "strong recommendation" for this manifestation to be included as part of the APS criteria revision². In the Phase III of the Development of New International Classification Criteria for APS, heart valve disease occurred with higher frequency in cases categorized as "highly likely" to have an APS diagnosis ${ }^{4}$.

\section{Dermatological manifestations}

\section{Livedo reticularis/racemosa}

Livedo is the most frequent dermatologic manifestations of APS (observed in $24.1 \%$ of patients of the Euro-phospholipid cohort) ${ }^{13,14}$, defined as a persisting violaceous, red, or blue reticular or mottled pattern of the skin, not reversible with rewarming ${ }^{1}$. It can consist of regular unbroken circles (livedo reticularis) or irregular-broken circles (livedo racemosa) ${ }^{15}$. Several associations have been reported with livedo, namely seizures, arterial events (and decreased venous events), cerebral or ocular vascular events, cognitive dysfunction, avascular necrosis, heart valve abnormalities and hypertension ${ }^{16-20}$. The report of the $14^{\text {th }}$ International Congress on aPL Technical Task Force on APS Clinical Features classified the evidence regarding livedo reticularis as of "moderate" quality, "recommending" its inclusion as part of the APS criteria revision ${ }^{2}$. In the Phase III of the Development of New International Classification Criteria for APS, microvascular disease (including livedo racemosa) occurred with higher frequency in cases categorized as "highly likely" to have an APS diagnosis ${ }^{4}$.

\section{Livedoid vasculopathy and skin ulcers}

Although livedoid vasculopathy is associated with APS, the exact prevalence is unclear ${ }^{15}$. It consists of a non-inflammatory occlusion of the small vessels of the skin due to thrombosis and deposition of fibrin in the vessel walls, mimicking vasculitis ${ }^{21}$. It mostly affects young women and presents as focal purpuric painful lesions that ultimately form irregularly shaped ulcers. These lesions heal slowly and leave porcelain-white, stellate, atrophic scars surrounded by telangiectasia, hemosiderin deposition, and hyperpigmentation (atrophie blanche $)^{15,22}$.

Skin ulcers in APS can occur due to various etiologies, including APS-related vasculopathy, secondary lesions in the context of prior thrombosis, or ulcerations secondary to warfarin treatment ${ }^{5}$.
In the Phase III of the Development of New International Classification Criteria for APS, microvascular disease (including livedoid vasculopathy) occurred with higher frequency in cases categorized as "highly likely" to have an APS diagnosis ${ }^{4}$.

\section{Ear, nose, and throat (ENT) manifestations}

\section{Sensorineural hearing loss}

The link between autoimmune diseases and sudden sensorineural hearing loss has been described as early as the 1970 s and $1980 s^{23,24}$, with various case reports and case series reporting this complication specifically in APS and systemic lupus erythematosus (SLE) patients ${ }^{25-29}$. Among the possible pathogenic mechanisms, microthrombosis of the cochlear vessels associated with $\mathrm{aPL}$ is a potential etiology ${ }^{30}$. A recent review found that most of the patients with sensorineural hearing loss and APS were males, with a clinical presentation including vertigo, tinnitus, and headache, and $75 \%$ of patients presented bilateral disease ${ }^{31}$. In terms of aPL profile, LA and aCL were found in equal proportions ${ }^{31}$. Regarding treatment, all patients were anticoagulated, and aspirin was added in $25 \%$ of the cases, with a complete resolution or improvement of the symptomology observed in $25 \%$ of the patients ${ }^{31}$.

\section{Endocrinological manifestations \\ Adrenal insufficiency due to hemorrhagic infarction}

Although rare $(0.4 \% \text { of APS patients })^{32}$, adrenal insufficiency is the most common endocrinologic manifestation of APS and can be its presenting symptom ${ }^{33}$. It has also been frequently observed as part of the multiorgan failure characteristic of catastrophic $\mathrm{APS}^{33}$. Data about this manifestation are mostly available from case reports and case series ${ }^{34-38}$. The pathogenesis is unclear, but some mechanisms are proposed: (i) rich adrenal arterial supply with a limited venous drainage predisposing patients to thrombosis, followed by hemorrhagic infarction of the adrenal glands; (ii) development of adrenal hemorrhage following surgery or anticoagulant therapy; and (iii) accumulation in the adrenal cells of late endosomes, which express epitopes recognized by $\mathrm{aPL}^{33}$. In a review of cases reported in the literature, the most frequent treatments were steroid replacement therapy ( $84 \%$ of patients), followed by anticoagulation (52\%) and aspirin $(6 \%)^{38}$. In the Phase III of the Development of New International Classification 
Criteria for APS, microvascular disease (including adrenal hemorrhage) occurred with higher frequency in cases categorized as "highly likely" to have an APS diagnosis ${ }^{4}$.

\section{Hematological manifestations}

\section{Hemolytic anemia}

The Euro-phospholipid cohort reported the presence of autoimmune hemolytic anemia (AlHA) in $9.7 \%$ of patients ${ }^{13}$, while a study of 308 APS patients found a prevalence of $10.4 \%^{39}$. This study also suggested an association between AlHA, arterial thrombosis, heart valve disease, epilepsy or chorea, and livedo reticularis $^{39}$. A potential mechanism for AlHA in APS is cross-reactivity between aPL and red cell membrane phospholipids ${ }^{40}$. A recent systematic review and meta-analysis attempting to clarify the relationship between aPL and AlHA found the highest prevalence of AlHA in SLE patients with APS/aPL, low/moderate prevalence in SLE patients without aPL, and a lower prevalence in primary APS ${ }^{41}$.

\section{Thrombocytopenia}

Thrombocytopenia is one of the most commonly present non-criteria manifestations, with a reported prevalence ranging from $16 \%$ to $53 \%$ in APS patients ${ }^{42}$. There is limited knowledge on the pathogenesis of thrombocytopenia in APS, but various mechanisms are proposed: (i) increased platelet destruction, either immune-mediated (caused by aPL or associated immune thrombocytopenic purpura), due to thrombotic microangiopathy (as in the case of catastrophic APS), or drug-induced; (ii) decreased platelet production; (iii) increased platelet pooling; and (iv) pseudothrombocytopenia ${ }^{43}$. Thrombocytopenia in APS is usually described as mild (70-120 × 109 platelets/L) and benign ${ }^{44}$; nevertheless, in a study of 51 APS patients with thrombocytopenia, 31\% received some form of specific treatment (either corticosteroids, intravenous immunoglobulin or rituximab) ${ }^{45}$. Regarding the disease course, in this same study, the authors observed that if thrombocytopenia was not present at diagnosis, patients had only $2.6 \%$ risk to develop it during follow-up ${ }^{45}$. Furthermore, thrombocytopenia was particularly related with a highrisk aPL profile (LA and triple positivity), but the decreased platelet count had no proven impact on the risk of major bleedings ${ }^{45}$. A tempting idea would be the possibility of thrombocytopenia serving as a marker for future development of SLE in APS patients, but different publications could not establish this association ${ }^{46-48}$. However, a study of 138 patients with aPL positivity and thrombocytopenia (i.e., fulfilling laboratory but not clinical criteria of APS) described a 5 times higher risk of future thrombosis in these patients compared with those with normal platelet counts ${ }^{49}$. The report of the $14^{\text {th }}$ International Congress on aPL Technical Task Force on APS Clinical Features classified the evidence regarding thrombocytopenia as of "low" quality, but "recommended" its inclusion as part of the APS criteria revision ${ }^{2}$. In the Phase III of the Development of New International Classification Criteria for APS, thrombocytopenia occurred with higher frequency in cases categorized as "highly likely" to have an APS diagnosis".

\section{Musculoskeletal manifestations}

\section{Ischemic bone necrosis}

There is an increased incidence of osteonecrosis in primary APS patients in the absence of other predisposing factors, suggesting an association between osteonecrosis and $\mathrm{aPL}^{20}$. The reported incidence varies between $0.9 \%$ and $20 \%$ in primary APS patients ${ }^{50,51}$. Regarding pathogenesis, aPL may play a role in osteonecrosis development by promoting thrombotic vasculopathy in the intraosseous microcirculation ${ }^{20}$. In a prospective study of 30 primary APS patients who had never received corticosteroids, $6(20 \%)$ had evidence of asymptomatic avascular necrosis on magnetic resonance imaging $(\mathrm{MRI})^{52}$. In the same study, avascular necrosis tended to develop more frequently in younger individuals, and livedo reticularis was more frequent in patients with avascular necrosis ${ }^{20}$.

\section{Neurological manifestations}

\section{Acute ischemic encephalopathy}

First described in association with APS in $1989^{53}$, acute ischemic encephalopathy has been observed in several patients with aPL ${ }^{54-56}$ and it was present in $1.1 \%$ of patients of the Euro-phospholipid cohort ${ }^{13}$. Clinical findings include confusion, asymmetrical quadriparesis, hyperreflexia, and bilateral extensor plantar responses, with imaging exams revealing cortical hypodensities on MRI ${ }^{57,58}$. In the Phase III of the Development of New International Classification Criteria for APS, microvascular disease (including acute ischemic encephalopathy) occurred with higher frequency in cases categorized as "highly likely" to have an APS diagnosis ${ }^{4}$. 


\section{Chorea}

Chorea is described as a rare complication of APS, with a prevalence of $1.3 \%$ in the Euro-phospholipid cohort $^{13}$, but constitutes the most common movement disorder associated with the disease. Though still uncertain, the pathophysiology may be related with (i) cerebral infarctions and white matter changes due to a thrombo-occlusive mechanism; or (ii) immunemediated damage against basal ganglia epitopes ${ }^{59}$. A study of 50 patients with APS and chorea showed a significant percentage of younger women and SLEassociated APS patients and described a possible association with the initiation of oral contraceptives ${ }^{60,61}$. The report of the $14^{\text {th }}$ International Congress on aPL Technical Task Force on APS Clinical Features classified the evidence regarding chorea as of "low" quality, but "recommended" its inclusion as part of the APS criteria revision ${ }^{2}$.

\section{Cognitive dysfunction}

The reported frequency of cognitive dysfunction in aPL-positive patients ranges from $19 \%$ to $40 \%$, with dementia observed in much lower percentages $(0 \%$ to $6 \%)^{62}$. Cognitive dysfunction is a broad term that encompasses different manifestations, and patients may report difficulty with memory, attention, and concentration, or the dysfunction may be subclinical and apparent only with neuropsychological testing ${ }^{63}$. A study of 60 APS patients found a higher frequency of cognitive impairment in comparison with matched controls, reporting also an increased risk for cognitive dysfunction in patients with livedo reticularis and white matter lesions on brain $\mathrm{MRI}^{19}$. Another study found cognitive dysfunction to be more common in aPL high-titer patients in comparison with moderate-titer patients ${ }^{19}$. Although it would be tempting to correlate cognitive deficits with cerebral ischemic lesions, while some studies of MRI in APS patients display high frequency of cortical, subcortical, and basal ganglia infarcts, others focusing specifically on cognition failed to demonstrate an increased numbers of infarcts in patients with APS with cognitive deficits compared with controls ${ }^{60}$.

\section{Epilepsy/seizures}

The prevalence of epilepsy in APS is reported to range from $3 \%$ to $10 \%$, with higher prevalence in SLE-associated APS $5,13,64$. Although the pathogenic mechanism is not clear, possibilities include: (i) occlusion of vessels supplying the nervous tissue and (ii) direct interaction of antibodies with phospholipids of neural cells ${ }^{65,66}$. Regarding clinical presentation, temporal lobe epilepsy is particularly prominent in APS ${ }^{67}$. The report of the $14^{\text {th }}$ International Congress on aPL Technical Task Force on APS Clinical Features classified the evidence regarding seizures as of "very low" quality, recommending against its inclusion as part of the APS criteria revision².

\section{Migraine}

In the Euro-phospholipid cohort ${ }^{13}$, migraine featured as the most common neurologic manifestation, being present in $20.2 \%$ of patients. In the literature, the reported prevalence ranges from $0 \%$ to $30 \%{ }^{68}$. Nevertheless, the association between aPL and migraine is still not categorical, with conflicting studies regarding this matter ${ }^{68}$. Among possible pathogenic mechanisms, platelet function abnormalities and interaction of LA with neuronal phospholipids such as sphingomyelin have been hypothesized ${ }^{68,69}$. In a review by Hughes ${ }^{70}$, the typical clinical picture is migraine (often premenstrual) starting in teenage years, with subsequent improvement and return in the 30s or 40s; additionally, a strong family history of headaches or migraine is reported, and visual or speech disturbance or transient ischemic attacks occur concurrently in some patients ${ }^{70}$. Anticoagulation is still considered the mainstay treatment, with a resolution or improvement of the migraine standing as an additional clue to its relationship with APS ${ }^{68,71,72}$. Nevertheless, the report of the $14^{\text {th }}$ International Congress on aPL Technical Task Force on APS Clinical Features classified the evidence regarding migraine as of "very low" quality, recommending against its inclusion as part of the APS criteria revision ${ }^{2}$.

\section{Transverse myelitis}

The prevalence of transverse myelitis in APS is estimated to be around $0.4-4 \% 59$. Plausible pathophysiological mechanisms of transverse myelitis in patients with aPL include: (i) vasculitis; (ii) arterial thrombosis resulting in ischemic cord necrosis; and (iii) direct interaction between aPL and spinal cord phospholipids ${ }^{2,73}$. Various studies additionally report an association between the presence of aPL and transverse myelitis in SLE patients ${ }^{74,75}$. The report of the $14^{\text {th }}$ International Congress on aPL Technical Task Force on APS Clinical 
Features classified the evidence regarding longitudinal myelitis as of "low" quality, but "recommended" its inclusion as part of the APS criteria revision".

\section{Pulmonary manifestations \\ Diffuse alveolar hemorrhage}

First described in association with APS in $1991^{76}$, diffuse alveolar hemorrhage is a rare manifestation of APS $(0.7 \%$ in the Euro-phospholipid cohort together with acute respiratory distress syndrome and pulmonary artery thrombosis) ${ }^{13}$, but occurs in $12 \%$ of catastrophic APS patients ${ }^{77}$. Possible mechanisms behind this complication in APS include: (i) aPL-induced pulmonary capillaritis; (ii) microvascular thrombosis generating alveoli hemorrhage; (iii) aPL activation of the mTOR kinase leading to endothelium proliferation and consequent vasculopathy; and (iv) complement activation $^{78}$. In a recent review of cases of alveolar hemorrhage associated with APS, this complication was the initial feature of APS in $11 \%$ of cases; $65 \%$ achieved remission, $55 \%$ experienced recurrent disease, and $21 \%$ died $^{78}$. Regarding treatment, it should be noted that anticoagulation has not been shown to be beneficial in preventing or treating alveolar hemorrhage in APS patients, with anticoagulation being usually transiently discontinued during the bleeding episode and later restarted depending on the patient's condition ${ }^{78}$. In the Phase III of the Development of New International Classification Criteria for APS, microvascular disease (including pulmonary hemorrhage) occurred with higher frequency in cases categorized as "highly likely" to have an APS diagnosis 4 .

\section{Pulmonary hypertension}

There is growing evidence on the association between pulmonary hypertension and the presence of $\mathrm{aPL}^{79}$. Among SLE patients, a meta-analysis found that aPL can identify patients at risk for pulmonary hypertension ${ }^{80}$. There are various pathogenic mechanisms proposed, including: (i) large vessel and small vessel thrombosis; (ii) pro-inflammatory effects of aPL; (iii) Libman-Sacks endocarditis and left-sided valvular disease; and (iv) chronic thromboemboli and associated endothelial remodeling ${ }^{79,81,82}$. The prevalence of this manifestation in the Euro-phospholipid cohort was $2.2 \%{ }^{13}$, while another European study of 114 APS patients displayed a prevalence of $3.5 \%$ in primary APS and $1.8 \%$ in APS associated with other autoimmune diseases ${ }^{83}$. The presence of aPL is suggested to be associated with pulmonary hypertension of across all the five WHO groups ${ }^{81}$. A review suggested that the outcome of pulmonary hypertension in aPL-positive patients seemed to be linked with the occurrence of new venous thromboembolic events or left-sided heart abnormalities ${ }^{79}$.

\section{Ophthalmological manifestations}

\section{Amaurosis fugax}

Ocular changes can be found in $8-88 \%$ of APS patients, with manifestations occurring mainly due to thrombotic events in central retinal vessels ${ }^{84,85}$. In the case of amaurosis fugax, if binocular, it usually represents central nervous system ischemia ${ }^{86}$. This manifestation was present in $2.2 \%$ of patients of the Euro-phospholipid cohort ${ }^{13}$. In a recent study featuring a cohort of 105 primary APS patients, amaurosis fugax starred as the most prevalent ophthalmological involvement, being present in $30(29 \%)$ patients, and associated with the presence of livedo reticularis, Raynaud's phenomenon, and $\mathrm{aCL}^{87}$.

\section{Renal manifestations}

\section{APS nephropathy}

The first reports of APS nephropathy date back to $1990^{88}$, with the description as a distinct clinical entity occurring in 1999. It comprises renal small vessel vasculopathy with thrombotic microangiopathy, fibrous intimal hyperplasia, arterial and arteriolar recanalizing thrombi, fibrous arterial occlusion, focal cortical atrophy, tubular thyroidization, and absence of vasculitis ${ }^{89-91}$. The clinical presentation includes hypertension, acute or chronic kidney injury, proteinuria (mild to nephrotic), and hematuria ${ }^{91,92}$. The prognosis is variable but includes high prevalence of chronic hypertension in most series, while proteinuria, nephrotic syndrome, chronic renal failure, or end-stage renal disease also occurs ${ }^{91}$. The report of the $14^{\text {th }}$ International Congress on aPL Technical Task Force on APS Clinical Features classified the evidence regarding APS nephropathy as of "moderate" quality, issuing a "strong recommendation" for it to be included as part of the APS criteria revision? In the Phase III of the Development of New International Classification Criteria for APS, chronic aPL-related nephropathy occurred with higher frequency in cases categorized as "highly likely" to have an APS diagnosis ${ }^{4}$. 


\section{Vascular manifestations}

\section{Superficial vein thrombosis}

Although common in APS $(11.7 \%$ of patients in the Euro-phospholipid cohort $)^{13}$, the limited evidence regarding the correlation between superficial vein thrombosis and APS/aPL together with the intent to avoid classifying other diseases as APS (e.g., Behçet's disease, where aPL and superficial vein thrombosis can coexist) has determined a maintained exclusion from the classification criteria ${ }^{2}$. Nevertheless, in a prospective cohort study of 92 patients with SLE and/or aPL with a median follow-up of 35 months, superficial vein thrombosis carried a hazard ratio of 7.45 for the occurrence of thromboembolic events, suggesting a possible prognostic significance $^{93}$. The report of the $14^{\text {th }}$ International Congress on aPL Technical Task Force on APS Clinical Features classified the evidence regarding superficial vein thrombosis as of "low" quality, but "suggested" its inclusion as part of the APS criteria revision?.

\section{Obstetric manifestations}

\section{Infertility}

The concept of a relationship between some infertility cases and APS/aPL, although tempting, is still controversial. Different pathogenic mechanisms could explain this link, namely (i) aPL interfering with oocyte development and uterine decidualization and (ii) neutrophil extracellular traps promoting coagulation ${ }^{94}$. A recent review analyzed 16 studies assessing aPL positivity rates in infertile women and control populations, while 10 studies showed aPL elevation in women with unexplained infertility comparing with healthy controls, six showed no significant differences ${ }^{94}$. The authors concluded that currently there is not enough evidence to support the routine testing of aPL in patients with infertility ${ }^{94}$.

\section{In vitro fertilization (IVF) failure}

Following the same reasoning as above, aPL have been hypothesized to be related with IVF failures ${ }^{95}$. However, this association is once again controversial. The aforementioned review also analyzed studies evaluating the relevance of aPL in women undergoing IVF. Among 33 studies, 15 showed some contribution of aPL to IVF failure, while 18 failed to show this association ${ }^{94}$. More importantly, the authors noted the presence of an association in some retrospective studies, while it was absent in most of the prospective studies ${ }^{94}$.

\section{Placenta-mediated complications}

Placenta-mediated complications, such as abruptio placentae and hematoma and late pre-eclampsia/intrauterine growth restriction (IUGR), have been reported as complications of APS patients in various case reports and cohorts ${ }^{96,97}$. While pre-eclampsia and IUGR before the $34^{\text {th }}$ week of gestation are included in the revised criteria ${ }^{1}$, those occurring afterward are not. It is hypothesized that early pregnancy complications are related to a direct inhibitory effect of aPL on the trophoblast cells, while late manifestations are attributable to placental dysfunction due to thrombotic and inflammatory changes ${ }^{98}$. In the Summary of the $9^{\text {th }}$ meeting of the European Forum on aPL, the concept of obstetric morbidity associated with APS (OMAPS) was discussed, including some of these manifestations: two miscarriages, late pre-eclampsia, abruptio placentae, late premature birth, and more than two unexplained IVF failures ${ }^{99}$. Nevertheless, a meta-analysis attempting to clarify the association between aPL and some late placenta-mediated complications (i.e., late fetal loss, pre-eclampsia, IUGR, and placental abruption) was unable to establish a categorical relationship due to significant heterogeneity and underpowered studies $^{100}$. The EUROAPS registry has gathered data regarding these obstetric patients with non-criteria manifestations ${ }^{101,102}$ and, in a publication with $1000 \mathrm{ob}$ stetric APS patients, two spontaneous abortions before 10 weeks of gestation were present in $9.5 \%$ of patients, IUGR after 34 weeks of gestation in $4.7 \%$, pre-eclampsia after 34 weeks of gestation in $4.6 \%$, placental hematoma in $1.3 \%$, and abruptio placentae in $1 \%{ }^{102}$. Nonetheless, the impact of each individual manifestation in APS patient is still unclear.

\section{Conclusion}

From the analysis of the available evidence regarding the different non-criteria manifestations it is notorious that, although relevant, their association with APS/aPL is still unclear or scarcely characterized in most cases. This notion reinforces the need for well-designed studies evaluating specific manifestations in homogeneous APS populations.

\section{Funding}

This research did not receive any specific grant from funding agencies in the public, commercial, or not-forprofit sectors. 


\section{Conflicts of interest}

The authors declare that they have no conflicts of interest.

\section{Ethical disclosures}

Protection of human and animal subjects. The authors declare that no experiments were performed on humans or animals for this study.

Confidentiality of data. The authors declare that no patient data appear in this article.

Right to privacy and informed consent. The authors declare that no patient data appear in this article.

\section{References}

1. Miyakis S, Lockshin MD, Atsumi T, Branch DW, Brey RL, Cervera R et al. International consensus statement on an update of the classification criteria for definite antiphospholipid syndrome (APS). J Thromb Haemost. 2006;4:295-306.

2. Abreu MM, Danowski A, Wahl DG, Amigo MC, Tektonidou M, Pacheco MS, et al. The relevance of "'non-criteria" clinical manifestations of antiphospholipid syndrome: $14^{\text {th }}$ international congress on antiphospholipid antibodies technical task force report on antiphospholipid syndrome clinical features. Autoimmun Rev. 2015;14:401-14.

3. Arachchillage DR, Machin SJ, Mackie IJ, Cohen H. Diagnosis and management of non-criteria obstetric antiphospholipid syndrome. Thromb Haemost. 2015;113:13-9.

4. Barbhaiya M, Erkan D, Ahmadzadeh $\mathrm{Y}$, Costenbader K, Naden R, Erkan $D$, et al. Development of new international classification criteria for Antiphospholipid syndrome: phase III case collection results. Ann Rheum Dis. 2020;79:64.

5. Xourgia E, Tektonidou MG. Management of non-criteria manifestations in antiphospholipid syndrome. Curr Rheumatol Rep. 2020;22:51.

6. Kolitz T, Shiber S, Sharabi I, Winder A, Zandman-Goddard G. Cardiac manifestations of antiphospholipid syndrome with focus on its primary form. Front Immunol. 2019;10:941

7. Brown JH, Doherty CC, Allen DC, Morton P. Fatal cardiac failure due to myocardial microthrombi in systemic lupus erythematosus. Br Med J (Clin Res Ed). 1988;296:1505.

8. Asherson RA, Cervera R, Piette JC, Font J, Lie JT, Burcoglu A, et al Catastrophic antiphospholipid syndrome. Clinical and laboratory features of 50 patients. Medicine (Baltimore) 1998;77:195-207.

9. Roldan CA. Valvular and coronary heart disease in systemic inflammatory diseases. Heart. 2008:94:1089-101.

10. Zuily S, Huttin O, Mohamed S, Marie PY, Selton-Suty C, Wahl D. Valvular heart disease in antiphospholipid syndrome. Curr Rheumatol Rep. 2013:15:320

11. Mattos $P$, Santiago MB. Association of antiphospholipid antibodies with valvulopathy in systemic lupus erythematosus: a systematic review. Clin Rheumatol. 2011;30:165-71.

12. Zuily S, Regnault V, Selton-Suty $C$, Eschwège V, Bruntz JF, Bode-Dotto E, et al. Increased risk for heart valve disease associated with antiphospholipid antibodies in patients with systemic lupus erythematosus. Circulation. 2011;124:215-24

13. Cervera R, Khamashta MA, Shoenfeld Y, Camps MT, Jacobsen S, Kiss $E$, et al. Morbidity and mortality in the antiphospholipid syndrome during a 5-year period: a multicentre prospective study of 1000 patients. Ann Rheum Dis. 2009;68:1428-32.

14. Pinto-Almeida T, Caetano M, Sanches M, Selores M. Cutaneous manifestations of antiphospholipid syndrome: a review of the clinical features, diagnosis and management. Acta Reumatol Port. 2013;38:1018.

15. Campos LM, Kiss MH, D’Amico EA, Silva CA. Antiphospholipid antibodies and antiphospholipid syndrome in 57 children and adolescents with systemic lupus erythematosus. Lupus. 2003:12:820-6.

16. Diógenes MJ, Diógenes PC, de Morais Carneiro RM, et al. Cutaneous manifestations associated with antiphospholipid antibodies. Int J Dermatol. 2004:43:632-7.

17. Francès C, Niang S, Laffitte E, Neto CC, Duarte FB, Holanda RR. Dermatologic manifestations of the antiphospholipid syndrome: two hundred consecutive cases. Arthritis Rheum. 2005:52:1785-93.
18. Toubi E, Krause I, Fraser A, Lev S, Stojanovich L, Rovensky J, et al. Livedo reticularis is a marker for predicting multi-system thrombosis in antiphospholipid syndrome. Clin Exp Rheumatol. 2005;23:499-504.

19. Erkan D, Barbhaiya M, George D, Sammaritano L, Lockshin M. Moderate versus high-titer persistently anticardiolipin antibody positive patients: are they clinically different and does high-titer anti-beta 2-glycoprotein-I antibody positivity offer additional predictive information? Lupus. 2010;19:613-9.

20. Tektonidou MG, Moutsopoulos HM. Osteoarticular manifestations of antiphospholipid syndrome. Rheum Dis Clin North Am. 2006;32:523-35.

21. Kapur SV, Oswal JS. Livedoid vasculopathy associated with antiphospholipid antibody presenting with leg ulcer. Indian J Pediatr. 2020;87: 1082-2.

22. Acland KM, Darvay A, Wakelin SH, Russell-Jones R. Livedoid vasculitis: a manifestation of the antiphospholipid syndrome? $\mathrm{Br} \mathrm{J}$ Dermatol. 1999;140:131-5

23. Caldarelli DD, Rejowski JE, Corey JP. Sensorineural hearing loss in lupus erythematosus. Am J Otol. 1986:7:210-3.

24. McCabe BF. Autoimmune sensorineural hearing loss. Ann Otol Rhinol Laryngol. 1979;88:585-9.

25. Galicia-López A, Anda-Garay JC, de la Peña GM. Bilateral sudden sensorineural hearing loss in a patient with microangiopathic antiphospholipid syndrome. Reumatol Clin. 2016;12:175-177.

26. Wiles NM, Hunt BJ, Callanan V, Chevretton EB. Sudden sensorineural hearing loss and antiphospholipid syndrome. Haematologica. 2006;91:Ecr46.

27. Suhail T, Ismail A. 022 Antiphospholipid syndrome associated withauto immune hearing loss. Rheumatology. 2018:57:246.

28. Hisashi K, Komune S, Komiyama S, Nakamura K. Sudden sensorineural hearing loss associated with anticardiolipin antibody. Nihon Jibiinkoka Gakkai Kaiho. 1996;99:1157-61.

29. Toubi E, BenDavid J, Kessel A, Podoshin L, Golan TD. Autoimmune aberration in sudden sensorineural hearing loss: association with anti-cardiolipin antibodies. Lupus. 1997;6:540-2.

30. Toubi E, Kessel A, Ben-David J, Podoshin L, Golan TD. The ear and antiphospholipid syndrome. In: Khamashta MA, editor. Hughes Syndrome: antiphospholipid Syndrome. London: Springer London; 2000. p. 82-8.

31. Riera JL, Del R Maliandi M, Musuruana JL, Cavallasca JA. Sudden sensorineural hearing loss in systemic lupus erythematosus and antiphospholipid syndrome: a clinical review. Curr Rheumatol Rev. 2020;16:84-91.

32. Cervera R, Boffa MC, Khamashta MA, Hughes GR. The Euro-Phospholipid project: epidemiology of the antiphospholipid syndrome in Europe. Lupus. 2009;18:889-93.

33. Uthman I, Salti I, Khamashta M. Endocrinologic manifestations of the antiphospholipid syndrome. Lupus. 2006:15:485-9.

34. Diana O, Mara V, Miguel M, Paiva S, Carrilho F. Addison's disease in antiphospholipid syndrome: a rare complication. Endocrinol Diabetes Metab Case Rep. 2018:2018:18-0118.

35. Fabio P, Francesca F, Corrado B, Federspil G, Rossato M. Acute adrenal failure as the heralding symptom of primary antiphospholipid syndrome: report of a case and review of the literature. Eur $\mathrm{J}$ Endocrinol. 2005:153:507-14.

36. Sanyal D, Raychaudhuri M. Primary adrenal insufficiency in case of antiphospholipid syndrome. Indian J Endocrinol Metab. 2013;17: S252-3.

37. Aldaajani H, Albahrani S, Saleh K, Alghanim K. Bilateral adrenal hemorrhage in antiphospholipid syndrome. Anticoagulation for the treatment of hemorrhage. Saudi Med J. 2018;39:829-33.

38. Espinosa G, Santos E, Cervera R, Piette JC, de la Red G, Gil V, et al. Adrenal involvement in the antiphospholipid syndrome: clinical and immunologic characteristics of 86 patients. Medicine (Baltimore). 2003;82:106-18.

39. Rottem M, Krause I, Fraser A, Stojanovich L, Rovensky J, Shoenfeld Y. Autoimmune hemolytic anaemia in the antiphospholipid syndrome. Lupus. 2006;15:473-7.

40. Dolors T, Joan-Carles R. Hematologic abnormalities in the antiphospholipid syndrome. Curr Rheumatol Rev. 2010;6:55-63.

41. Ames PRJ, Merashli M, Bucci T, Pastori D, Pignatelli P, Arcaro A, et al. Antiphospholipid antibodies and autoimmune haemolytic anaemia: a systematic review and meta-analysis. Int J Mol Sci. 2020;21:4120.

42. Krause I, Blank M, Fraser A, Lorber M, Stojanovich L, Rovensky J, et al. The association of thrombocytopenia with systemic manifestations in the antiphospholipid syndrome. Immunobiology. 2005;210:749-54.

43. Artim-Esen B, Diz-Küçükkaya R, \nanç M. The significance and management of thrombocytopenia in antiphospholipid syndrome. Curr Rheumatol Rep. 2015;17:14

44. Cuadrado MJ, Mujic F, Muñoz E, Khamashta MA, Hughes GR. Thrombocytopenia in the antiphospholipid syndrome. Ann Rheum Dis. 1997:56:194-6.

45. Yelnik CM, Nguyen Y, Le Guern V, Hachulla E, Lambert M. Thrombocytopenia in primary antiphospholipid syndrome, a marker of high-risk patients? Eur J Intern Med. 2020;74:106-7. 
46. Andreoli L, Pregnolato F, Burlingame RW, Fanelli V, Allegri F, Radice A, et al. Primary antiphospholipid syndrome evolving into systemic lupus erythematosus: may antinucleosome antibodies be predictive? Reumatismo. 2008:60:185-91.

47. Gómez-Puerta JA, Martín H, Amigo MC, Aguirre MA, Camps MT, Cuadrado $\mathrm{MJ}$, et al. Long-term follow-up in 128 patients with primary antiphospholipid syndrome: do they develop lupus? Medicine (Baltimore). 2005; 84:225-30.

48. Freire PV, Watanabe E, dos Santos NR, Bueno C, Bonfá E, de Carvalho JF. Distinct antibody profile: a clue to primary antiphospholipid syndrome evolving into systemic lupus erythematosus? Clin Rheumatol. 2014;33:349-53.

49. Pablo RD, Muñoz P, López-Hoyos M, Calvo V, Riancho L, Martínez-Taboada VM. Thrombocytopenia as a thrombotic risk factor in patients with antiphospholipid antibodies without disease criteria. Med Clin (Barc). 2017; 148:394-400.

50. Noureldine MH, Khamashta MA, Merashli M, Sabbouh T, Hughes GR, Uthman I. Musculoskeletal manifestations of the antiphospholipid syndrome. Lupus. 2016;25:451-62.

51. Cervera R, Piette JC, Font J, Khamashta MA, Shoenfeld Y, Camps MT, et al. Antiphospholipid syndrome: clinical and immunologic manifestations and patterns of disease expression in a cohort of 1,000 patients. Arthritis Rheum. 2002;46:1019-27.

52. Tektonidou MG, Malagari K, Vlachoyiannopoulos PG, Kelekis DA, Moutsopoulos HM. Asymptomatic avascular necrosis in patients with primary antiphospholipid syndrome in the absence of corticosteroid use: a prospective study by magnetic resonance imaging. Arthritis Rheum. 2003;48:732-6.

53. Briley DP, Coull BM, Goodnight SH Jr. Neurological disease associated with antiphospholipid antibodies. Ann Neurol. 1989;25:221-7.

54. Parikh T, Shifteh K, Lipton ML, Bello JA, Brook AL. Deep brain reversible encephalopathy: association with secondary antiphospholipid antibody syndrome. Am J Neuroradiol. 2007;28:76-8.

55. Thomas $\mathrm{P}$, Lebrun C, Mahagne MH, Desnuelles C, Chatel M. Ischemic encephalopathy in primary antiphospholipid syndrome. Rev Neurol (Paris). 1993:149:336-9.

56. Chinnery PF, Shaw PJ, Ince PG, Jackson GH, Bishop RI. Fulminant encephalopathy due to the catastrophic primary antiphospholipid syndrome. J Neurol Neurosurg Psychiatry. 1997;62:300-1.

57. Gerard Espinosa RC. Unusual manifestations of the antiphospholipid syndrome. Int J Clin Rheumatol. 2009;4:189-202.

58. Sanna G, Bertolaccini ML, Cuadrado MJ, Khamashta MA, Hughes GR. Central nervous system involvement in the antiphospholipid (Hughes) syndrome. Rheumatology. 2003;42:200-13.

59. Fleetwood T, Cantello R, Comi C. Antiphospholipid syndrome and the neurologist: from pathogenesis to therapy. Front Neurol. 2018:9:1001.

60. Graf J. Central nervous system manifestations of antiphospholipid syndrome. Rheum Dis Clin North Am. 2017;43:547-60.

61. Cervera R, Asherson RA, Font J, Tikly M, Pallarés L, Chamorro A, et al. Chorea in the antiphospholipid syndrome. Clinical, radiologic, and immunologic characteristics of 50 patients from our clinics and the recent literature. Medicine (Baltimore). 1997;76:203-12.

62. Yelnik CM, Kozora E, Appenzeller S. Cognitive disorders and antiphospholipid antibodies. Autoimmun Rev. 2016;15:1193-8.

63. Erkan D, Kozora E, Lockshin MD. Cognitive dysfunction and white matter abnormalities in antiphospholipid syndrome. Pathophysiology. 2011;18:93-102.

64. Shoenfeld Y, Lev S, Blatt I, Blank M, Font J, von Landenberg P, et al. Features associated with epilepsy in the antiphospholipid syndrome. J Rheumatol. 2004:31:1344-8.

65. Rosati A, Guerrini R, Cimaz R. Lupus, antiphospholipid syndrome and epilepsy: an update. Lupus. 2016;26:3-5.

66. Cimaz R, Guerrini R. Epilepsy in lupus. Lupus. 2008;17:777-9.

67. Noureldine MA, Harifi G, Haydar AA, Berjawi A, Nader M, Elnawar R, et al. AB0487 antiphospholipid syndrome and epilepsy: where do we stand? Ann Rheum Dis. 2016;75:1072.

68. Noureldine MH, Haydar AA, Berjawi A, Elnawar R, Sweid A, Khamashta MA, et al. Antiphospholipid syndrome (APS) revisited: would migraine headaches be included in future classification criteria? Immunol Res. 2017;65:230-41

69. Harris EN, Gharavi AE, Hegde U, Derue G, Morgan SH, Englert H, et al. Anticardiolipin antibodies in autoimmune thrombocytopenic purpura. $\mathrm{Br} J$ Haematol. 1985;59:231-4.

70. Hughes GR. Migraine, memory loss, and "multiple sclerosis". Neurological features of the antiphospholipid (Hughes') syndrome. Postgrad Med J. 2003;79:81-3.

71. Erkan D, Aguiar CL, Andrade D, Cohen H, Cuadrado MJ, Danowski A, et al. $14^{\text {th }}$ international congress on antiphospholipid antibodies: task force report on antiphospholipid syndrome treatment trends. Autoimmun Rev. 2014;13:685-96.

72. Hughes GR. Hughes syndrome (the antiphospholipid syndrome): ten clinical lessons. Autoimmun Rev. 2008;7:262-6.

73. Arnson Y, Shoenfeld Y, Alon E, Amital H. The antiphospholipid syndrome as a neurological disease. Semin Arthritis Rheum. 2010;40:97-108.
74. D'Cruz DP, Mellor-Pita S, Joven B, Sanna G, Allanson J, Taylor J, et al. Transverse myelitis as the first manifestation of systemic lupus erythematosus or lupus-like disease: good functional outcome and relevance of antiphospholipid antibodies. J Rheumatol. 2004;31:280-5.

75. Kovacs B, Lafferty TL, Brent LH, DeHoratius RJ. Transverse myelopathy in systemic lupus erythematosus: an analysis of 14 cases and review of the literature. Ann Rheum Dis. 2000;59:120-4.

76. Hillerdal G, Hägg A, Licke G, Wegenius G, Scheibenpflug L. Intra-alveolar haemorrhage in the anticardiolipin antibody syndrome. Scand J Rheumatol. 1991;20:58-62.

77. Rodríguez-Pintó I, Moitinho M, Santacreu I, Shoenfeld Y, Erkan D, Espinosa G, et al. Catastrophic antiphospholipid syndrome (CAPS): descriptive analysis of 500 patients from the international CAPS registry. Autoimmun Rev. 2016;15:1120-4.

78. Stoots SA, Lief L, Erkan D. Clinical insights into diffuse alveolar hemorrhage in antiphospholipid syndrome. Curr Rheumatol Rep. 2019;21:56.

79. Zuily S, Wahl D. Pulmonary hypertension in antiphospholipid syndrome. Curr Rheumatol Rep. 2015;17:4.

80. Zuily S, Domingues V, Suty-Selton C, Eschwège V, Bertoletti L, Chaouat $A$, et al. Antiphospholipid antibodies can identify lupus patients at risk of pulmonary hypertension: a systematic review and meta-analysis. Autoimmun Rev. 2017;16:576-86.

81. Parthvi R, Sikachi RR, Agrawal A, Adial A, Vulisha A, Khanijo S, et al. Pulmonary hypertension associated with antiphospholipid antibody: call for a screening tool? Intractable Rare Dis Res. 2017;6:163-71.

82. Kasthuri RS, Roubey RA. Pulmonary hypertension and the antiphospholipid syndrome. Adv Pulmonary Hypertens. 2008;7:286-91.

83. Vianna JL, Khamashta MA, Ordi-Ros J, Font J, Cervera R, Lopez-Soto A, et al. Comparison of the primary and secondary antiphospholipid syndrome: a European multicenter study of 114 patients. Am J Med. 1994;96:3-9.

84. Emmi G, Silvestri E, Squatrito D, Ciucciarelli L, Cameli AM, Denas G, et al. An approach to differential diagnosis of antiphospholipid antibody syndrome and related conditions. ScientificWorldJournal. 2014;2014:341342.

85. Yehudai D, Shoenfeld Y, Toubi E. Looking into the eyes of patients with antiphospholipid syndrome. Clin Rev Allergy Immunol. 2007:32:192-7.

86. Utz VM, Tang J. Ocular manifestations of the antiphospholipid syndrome. Br J Ophthalmol 2011;95:454-9.

87. Franco AM, Medina FM, Balbi GG, Levy RA, Signorelli F. Ophthalmologic manifestations in primary antiphospholipid syndrome patients: a cross-sectional analysis of a primary antiphospholipid syndrome cohort (APS-Rio) and systematic review of the literature. Lupus. 2020;29:1528-43.

88. D'Agati V, Kunis C, Williams G, Appel GB. Anti-cardiolipin antibody and renal disease: a report three cases. J Am Soc Nephrol. 1990;1:777-84.

89. Tektonidou MG. Antiphospholipid syndrome nephropathy: from pathogenesis to treatment. Front Immunol. 2018:9:1181.

90. Nochy D, Daugas E, Droz D, Beaufils H, Grünfeld JP, Piette JC, et al. The intrarenal vascular lesions associated with primary antiphospholipid syndrome. J Am Soc Nephrol. 1999;10:507-18.

91. Turrent-Carriles A, Herrera-Félix JP, Amigo MC. Renal involvement in antiphospholipid syndrome. Front Immunol. 2018;9:1008.

92. Sciascia S, Cuadrado MJ, Khamashta M, Roccatello D. Renal involvement in antiphospholipid syndrome. Nat Rev Nephrol. 2014;10:279-89.

93. Zuily S, Regnault V, Guillemin F, Kaminsky P, Rat AC, Lecompte T, et al. Superficial vein thrombosis, thrombin generation and activated protein $C$ resistance as predictors of thromboembolic events in lupus and antiphospholipid patients. A prospective cohort study. Thromb Res. 2013;132:e1-7.

94. El Hasbani G, Khamashta M, Uthman I. Antiphospholipid syndrome and infertility. Lupus. 2020;29:105-17.

95. Kaider AS, Kaider BD, Janowicz PB, Roussev RG. Immunodiagnostic evaluation in women with reproductive failure. Am J Reprod Immunol. 1999;42:335-46.

96. Ruffatti A, Chiarelli S, Favaro M, Borghi MO, Casonato A, Tonello M, et al. Could placental abruption be an antiphospholipid antibody related disorder? Clin Exp Rheumatol. 2004;22:380-1.

97. Belhocine M, Coutte L, Silva NM, Morel N, Guettrot-Imbert G, Paule R, et al. Intrauterine fetal deaths related to antiphospholipid syndrome: a descriptive study of 65 women. Arthritis Res Ther. 2018;20:249.

98. Schreiber K, Hunt BJ. Managing antiphospholipid syndrome in pregnancy. Thromb Res. 2019;181 Suppl 1:S41-6.

99. Swadzba J, Sydor WJ, Kolodziejczyk J, Musial J. Summary of the $9^{\text {th }}$ meeting of the European forum on antiphospholipid antibodies. Lupus. 2014;23:395-9.

100. Abou-Nassar K, Carrier M, Ramsay T, Rodger MA. The association between antiphospholipid antibodies and placenta mediated complications: a systematic review and meta-analysis. Thromb Res. 2011;128:77-85.

101. Alijotas-Reig J, Ferrer-Oliveras R, Ruffatti A, Tincani A, Lefkou E, Bertero MT, et al. The European registry on obstetric antiphospholipid syndrome (EUROAPS): a survey of 247 consecutive cases. Autoimmun Rev. 2015;14:387-95.

102. Alijotas-Reig J, Esteve-Valverde E, Ferrer-Oliveras R, LLurba E, Ruffatti A, Tincani A, et al. Comparative study between obstetric antiphospholipid syndrome and obstetric morbidity related with antiphospholipid antibodies. Med Clin. 2018;151:215-22. 